\title{
Myofibroblastic reaction is a common event in metastatic disease of breast carcinoma: a descriptive study
}

\author{
Xavier Catteau ${ }^{1,2,5^{*}}$, Philippe Simon ${ }^{2,3}$ and Jean-Christophe Noël ${ }^{2,4}$
}

\begin{abstract}
Background: The modification of stromal components with the disappearance of CD34 positive fibrocytes and by contrast the acquisition of smooth-muscle actin positive myofibroblasts is a frequent event in breast carcinomas but has been little studied in its metastatic sites. Therefore, the aim of the present study is to examine the stromal expression of CD34 and SMA in lymph node and liver metastases which are two of the most frequent metastatic breast cancer sites.
\end{abstract}

Methods: The distribution of CD34 fibrocytes and SMA myofibroblasts has been studied by immunohistochemistry in 41 lymph node and 36 liver metastases from patients with invasive carcinoma of no special type.

Results: No CD 34 fibrocytes were noted in the stroma of metastasis. By contrast, smooth-muscle actin stromal expression was observed in $95.1 \%$ of lymph node and $97.2 \%$ of liver metastases, independently of histological features of tumours.

Conclusions: Myofibroblasts represent a major and constant component in the metastatic tumoral stroma of breast carcinoma highlighting that these cells could play an active role in tumour cells proliferation and spread.

Virtual Slides: The virtual slide(s) for this article can be found here: http://www.diagnosticpathology.diagnomx.eu/ vs/13000_2014_196

Keywords: Myofibroblasts, Breast carcinoma, SMA, CD34, Lymph node, Liver, Metastasis

\section{Background}

The importance of the stromal microenvironment has been suggested to play a major role in breast carcinoma by promoting tumour growth, progression and invasion [1-4]. In particular according to these data we and others have clearly demonstrated that the loss of CD34 fibrocytes and acquisition of peritumoral myofibroblasts expressing smooth muscle actin (SMA) is a fundamental step both in ductal carcinoma in situ (DCIS) and invasive carcinoma of no special type (NST) $[5,6]$. If the acquisition of a myofibroblastic differentiation is an important data in peritumoral connective tissue remodeling [4], the morphological characterization of stromal microenvironment and particularly of myofibroblastic peritumoral cells

\footnotetext{
*Correspondence: xavier.catteau06@gmail.com

'Institute of Pathology and Genetics, Gosselies, Belgium

${ }^{2}$ Faculty of Medicine, Université Libre de Bruxelles, Brussels, Belgium

Full list of author information is available at the end of the article
}

in metastatic location is less understood. In preliminaries studies, some authors have suggested that the acquisition of a myofibroblastic differentiation could play a role in metastatic colonic adenocarcinoma [7] but however, until now, these data have not been clearly described in breast metastatic sites. Therefore, to clarify this issue, the aim of the present study is to assess by immunohistochemistry, the topographic distribution of CD 34 positive fibrocytes and SMA positive myofibroblasts both in axillary lymph node and liver metastases which are frequent in breast carcinoma and strongly associated with an increased risk of distant metastasis and poor overall survival [8].

\section{Methods}

\section{Study population}

We used a computer database from the Pathology and Genetics Institute (IPG) to identify 77 consecutive patients diagnosed between January 2008 and December 2012 with 
lymph node $(n=41)$ and liver metastasis $(n=36)$. The study protocol was approved by the institutional ethics (Ethics Committee Erasme Hospital) and research review boards. The belgian number (number of agreation) of this committee is OM021. The reference for this study is P2012/191. Consent has been established by the local ethics committee and is in accordance with Belgian and International law. For each patient, the following parameters including age, TNM classification, tumour grade and tumour size were performed according to the $4^{\text {th }}$ edition of WHO classification and are summarized in the Table 1.

\section{Immunohistochemistry}

The specimens were fixed in histology-grade $4 \%$ buffered formalin. Series paraffin sections were stained with haematoxylin and eosin and immunohistochemical detection was performed according to the manufacturer's protocols (Table 2). We used a fully automated immunohistochemical system (Autostainer Link A48 Dako).

\section{Semi-quantitative Assessment of Immunohistochemistry}

We compared the distribution of CD34 and SMA between stromal areas located within the metastasis with areas of normal liver and lymph node tissue. The immunoreactivity of CD34 and SMA was assessed semiquantitatively in the free tissue and the tumour. The percentage of stromal cells expressing each antigen was graded as "0", “+”, “++", “+++", “++++" when up to $5 \%$, more than $5 \%$ and up to $25 \%$, more than $25 \%$ and up to $50 \%$, more than $50 \%$ and up to $75 \%$ or more than $75 \%$ of stromal cells, disclosed immunoreactivity, respectively. Percentages were assessed by two independent observers, assuming that a high-power microscopic field (objective $\times 40$, microscopic magnification: $\times 400$ ) harboured 100 stromal cells (range: $75-150$ ) as previously described [9]. The relationship between the staining

Table 1 Clinicopathological data of the study population

\begin{tabular}{lll}
\hline & $\begin{array}{l}\text { Liver metastases } \\
\mathbf{N}=\mathbf{3 6}\end{array}$ & $\begin{array}{l}\text { Lymph node } \\
\text { metastases } \mathbf{N}=\mathbf{4 1}\end{array}$ \\
\hline No. & No. \\
Mean & 59.6 & 59 \\
Range & $34-86$ & $37-86$ \\
Primary tumour size & & \\
T1 $(0.1-2 \mathrm{~cm})$ & 18 & 21 \\
T2 $(>2-5 \mathrm{~cm})$ & 14 & 17 \\
T3 $(>5 \mathrm{~cm})$ & 4 & 3 \\
Primary tumour grade & & 8 \\
Grade 1 & 3 & 22 \\
Grade 2 & 23 & 11 \\
Grade 3 & 10 & \\
\hline
\end{tabular}

Table 2 Antibodies used in this study

\begin{tabular}{llllll}
\hline Antigen & Clone & & Dilution & Source & $\begin{array}{l}\text { Catalog } \\
\text { number }\end{array}$ \\
\hline CD 34 & QBEnd-10 & $\begin{array}{l}\text { Monoclonal } \\
\text { Mouse }\end{array}$ & $\begin{array}{l}\text { Ready-to- } \\
\text { use }\end{array}$ & Dako & IR63261 \\
Vimentine & V9 & $\begin{array}{l}\text { Monoclonal } \\
\text { Mouse }\end{array}$ & $\begin{array}{l}\text { Ready-to- } \\
\text { use }\end{array}$ & Dako & IR63061 \\
a-SMA & 1A4 & $\begin{array}{l}\text { Monoclonal } \\
\text { Mouse }\end{array}$ & $\begin{array}{l}\text { Ready-to- } \\
\text { use }\end{array}$ & Dako & IR00611 \\
CKAE1/AE3 & AE1/AE3 & $\begin{array}{l}\text { Monoclonal } \\
\text { Mouse }\end{array}$ & $\begin{array}{l}\text { Ready-to- } \\
\text { use }\end{array}$ & Dako & IR05361 \\
& & & & & \\
\hline
\end{tabular}

pattern of SMA and different clinical and histological features (age, tumour size and grade, TNM classification) was compared using a Chi-squared test. A p value $<0.05$ was considered statistically significant. All analyses were performed using Statistica ${ }^{\oplus}$.

\section{Results}

CD 34 and SMA expression in lymph node metastases In the normal lymph node, CD34 expression was limited both on the capsule and pericapsular fibrocytes but also in vessels within the parenchyma. CD34 fibrocytes were totally absent in peritumoral stroma and the immunoreactivity was restricted to the vasculature. By contrast, myofibroblasts were present in peritumoral stroma in $95 \%$ of cases with in a majority of cases more than $50 \%$ of stromal cells positive but this expression was not statistically correlated with clinical or pathological features $(p>0.05)$ (Tables 3 and 4$)$. The peritumoral myofibroblasts surrounded intimately the malignant cells (Figure 1). In the capsule both in the normal and peritumoral areas, a strong immunoreactivity for SMA was also observed. Lastly, in normal area, the reticular dendritic cells, stromal cells with myoïd features and vascular walls showed as previously described a discrete to moderate reactivity for SMA [10-12].

\section{34 and SMA expression in liver metastases}

In normal liver parenchyma, CD 34 expression was limited to vascular walls and focal immunoreactivity in portal tract. In the peritumoral stroma as in the lymph node, the immunoreactivity was restricted to the vasculature. Myofibroblasts are found intimately surrounding tumoral metastatic cells in peritumoral stroma in $97 \%$ of cases and like in lymph node was not statistically correlated with clinical and pathological features (Tables 3 and 4)

Table 3 Stromal SMA expression in lymph node and liver metastatic sites

\begin{tabular}{lllll}
\hline SMA expression & $\mathbf{0}$ & $\boldsymbol{+}$ or $\boldsymbol{+ +}$ & $\mathbf{+ + +}$ or ++++ & Total \\
\hline Lymph node & $2(5 \%)$ & $5(12 \%)$ & $34(83 \%)$ & 41 \\
Liver & $1(3 \%)$ & $3(8 \%)$ & $32(89 \%)$ & 36 \\
\hline
\end{tabular}


Table 4 Relation of SMA stromal expression and clinicopathological features

\begin{tabular}{|c|c|c|c|c|c|c|}
\hline & \multicolumn{2}{|c|}{$\begin{array}{l}\text { Lymph node } \\
\text { metastases }\end{array}$} & \multirow[b]{2}{*}{$\mathrm{p}$} & \multicolumn{2}{|c|}{ Liver metastases } & \multirow[b]{2}{*}{$p$} \\
\hline & $\begin{array}{l}\text { Strong } \\
\text { expression }\end{array}$ & $\begin{array}{l}\text { Weak } \\
\text { expression }\end{array}$ & & $\begin{array}{l}\text { Strong } \\
\text { expression }\end{array}$ & $\begin{array}{l}\text { Weak } \\
\text { expression }\end{array}$ & \\
\hline \multicolumn{7}{|l|}{ Age } \\
\hline$\leq 40$ & 3 & 0 & & 12 & 2 & \\
\hline$>40$ & 31 & 7 & 0.4 & 20 & 2 & 0.6 \\
\hline \multicolumn{7}{|l|}{$\begin{array}{l}\text { Tumour } \\
\text { grade }\end{array}$} \\
\hline G1 & 6 & 2 & & 2 & 1 & \\
\hline G2 & 17 & 4 & & 21 & 2 & \\
\hline G3 & 11 & 1 & 0.6 & 9 & 1 & 0.9 \\
\hline \multicolumn{7}{|l|}{$\begin{array}{l}\text { Tumour } \\
\text { size }(\mathrm{mm})\end{array}$} \\
\hline$\leq 10$ & 4 & 2 & & 3 & 1 & \\
\hline $\begin{array}{l}>10 \text { and } \\
\leq 20\end{array}$ & 14 & 2 & & 12 & 2 & \\
\hline$>20$ & 16 & 3 & 0.4 & 17 & 1 & 0.5 \\
\hline
\end{tabular}

(Figure 2). In normal liver area, as previously described, both hepatic stellate cells (Ito cells) in perisinusoidal spaces, portal tracts and vascular walls were positive for SMA [13].

\section{Discussion}

In preliminary papers, we have previously described that the stromal reaction and in particular tumor-associated myofibroblasts which are prominent in this stroma is a common feature both in situ and invasive breast carcinomas. In the present study, for the first time, we have demonstrated that myofibroblastic reaction was also common both in lymph node and liver metastases.

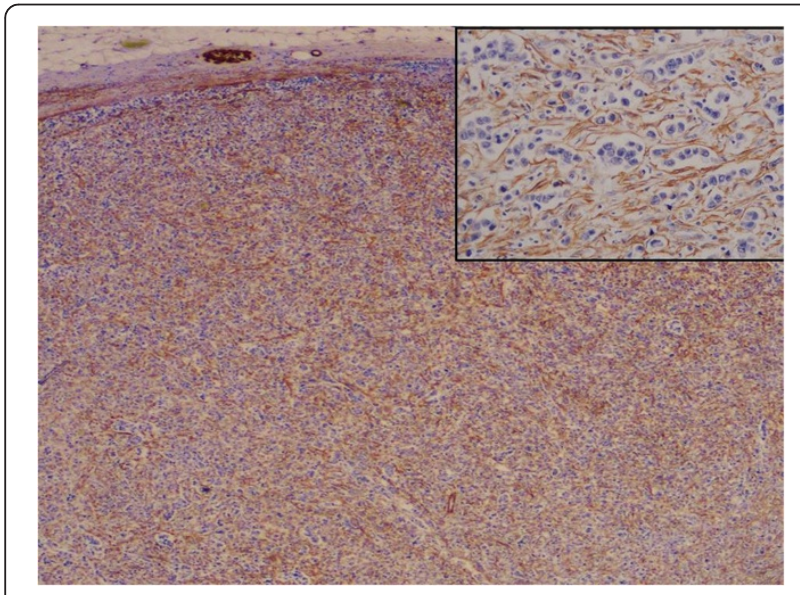

Figure 1 Typical example of SMA positive myofibroblasts within lymph node metastasis of invasive mammary carcinoma of NST (x100). Note that the myofibroblasts surround intimately the cancer cells at high power view (inset; $\times 400$ ).

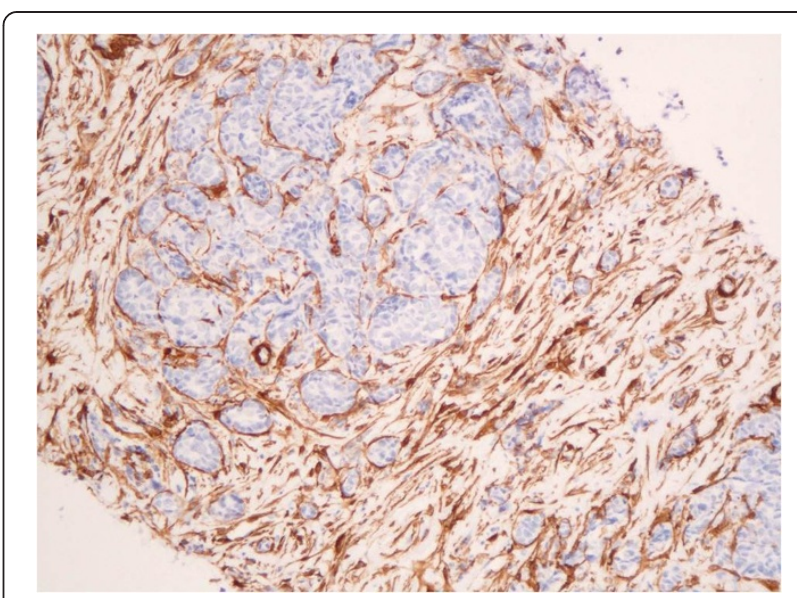

Figure 2 Myofibroblastic reaction within peritumoral stroma in liver metastasis $(x 200)$.

Indeed, in more than $90 \%$ of metastatic lymph node and liver metastatic cases, a peritumoral myofibroblastic reaction is present and the myofibroblasts generally surrounded intimately the tumoral cells. In addition, like in primary breast carcinoma, we have not observed CD 34 fibrocytes in the stroma and the immunoreactivity for this marker was restricted to the vascular walls, which possibly represent "neovessels".

In primary breast carcinoma, we have previously demonstrated that one of the potential origin of this peritumoral myofibroblasts is the transformation of resident fibrocytes $C D 34$ positive into myofibroblats by the way of the TGF- $ß 1 /$ TGF- $\beta 1$ receptor. However, the precursor of these myofibroblasts remains hypothetical in metastatic process.

In liver, we have could demonstrate like others, firstly that myofibroblasts were absent in normal parenchyma and secondly that SMA positivity was observed in vascular walls, portal tract stroma and hepatic perisinusoidal cells [13]. Therefore, as suggested by several authors in liver fibrosis, these cells could be potential precursor for myofibroblasts, which constitute the major source of collagen deposits $[14,15]$. By analogy, in the lymph node, stromal cells from the capsule, stromal cells with myoïd features and endothelial cells are potential precursors of myofibroblasts. In addition, both in lymph node and liver metastases, generation of myofibroblast either by epithelial-mesenchymal transition (EMT) process from epithelial carcinomatous cells, resident mesenchymal stem cells, or from totipotential bone marrow cells is still debate $[16,17]$.

If the myofibroblastic reaction seems a constant event both in breast carcinoma lymph node and liver metastases, until now, it is unclear whether this event is favourable to development of the metastatic process or by opposition is just a secondary passive reaction remains unsettled. In 
diverse primary carcinomatous processes including breast carcinoma, myofibroblasts promote tumour growth, invasion and angiogenesis through the paracrine effects of multiple factors including TGF- $\beta 1$ and matrixmetalloproteinases [18]. However, these factors are actually poorly characterized in metastatic process actually.

\section{Conclusions}

In summary, the presence of activated myofibroblasts in lymph node and liver metastases of breast carcinoma highlights the importance of the microenvironment in supporting cancers. Understanding the relationship between myofibroblasts and metastases is not just of prognostic significance, it could provide a new therapeutic target for the treatment of advanced cancer.

\section{Abbreviations \\ SMA: Smooth-muscle actin; DCIS: Ductal carcinoma in situ; NST: No special type; TGF-ß: Transforming growth factor-beta; EMT: Epithelial-mesenchymal transition; MMP: Matrix metalloproteinases.}

\section{Competing interests}

This study was supported by IRSPG (Institut de Recherche Scientifique de Pathologie et de Génétique).

\section{Author's contributions}

XC, PS, JCN conceived the study and participated in its design. XC and JCN provided formalin-fixed, paraffin-embedded archived patient materials for the study. IF and BC performed immunostaining. XC and JCN conducted pathologic reviews and clinical data evaluations. $X C$ performed statistical analyses. XC and JCN conducted in vivo experiments. XC and JCN drafted the manuscript. All authors read, edited and approved the final manuscript.

\section{Acknowledgments}

We thank Isabelle Fayt and Benedicte Culot for their help with processing histological specimens.

\section{Author details}

${ }^{1}$ Institute of Pathology and Genetics, Gosselies, Belgium. ${ }^{2}$ Faculty of Medicine, Université Libre de Bruxelles, Brussels, Belgium. ${ }^{3}$ Gynaecology Unit, Erasme University Hospital-Université libre de Bruxelles, Brussels, Belgium. ${ }^{4}$ Gynaecopathology Unit, Pathology Department, Erasme University Hospital-Université Libre de Bruxelles, Brussels, Belgium. ${ }^{5}$ Department of Pathology, Institute of Pathology and Genetics, 25, Avenue Georges Lemaître, Gosselies 6041, Belgium.

Received: 6 August 2014 Accepted: 7 October 2014

Published online: 22 October 2014

\section{References}

1. Bhowmick NA, Neilson EG, Moses HL: Stromal fibroblasts in cancer initiation and progression. Nature 2004, 432:332-337.

2. Cortez E, Roswall P, Pietras K: Functional subsets of mesenchymal cell types in the tumor microenvironment. Semin Cancer Biol 2014, 25:3-9.

3. De Wever O, Van Bockstal M, Mareel M, Hendrix A, Bracke M: Carcinomaassociated fibroblasts provide operational flexibility in metastasis. Semin Cancer Biol 2014, 25:33-46.

4. Hinz B, Phan SH, Thannickal VJ, Prunotto M, Desmouliere A, Varga J, De Wever O, Mareel M, Gabbiani G: Recent developments in myofibroblast biology: paradigms for connective tissue remodeling. Am J Pathol 2012, 180:1340-1355.

5. Catteau $X$, Simon $P$, Vanhaeverbeek $M$, Noel JC: Variable stromal periductular expression of CD34 and smooth muscle actin (SMA) in intraductal carcinoma of the breast. PLoS One 2013, 8:e57773.

6. Catteau X, Simon P, Noel JC: Myofibroblastic stromal reaction and lymph node status in invasive breast carcinoma: possible role of the TGF-beta1/ TGF-betaR1 pathway. BMC Cancer 2014, 14:499.
7. Yeung TM, Buskens C, Wang LM, Mortensen NJ, Bodmer WF: Myofibroblast activation in colorectal cancer lymph node metastases. Br J Cancer 2013, 108:2106-2115.

8. Carter $\mathrm{CL}$, Allen C, Henson DE: Relation of tumor size, lymph node status, and survival in 24,740 breast cancer cases. Cancer 1989, 63:181-187.

9. Barth PJ, Moll R, Ramaswamy A: Stromal remodeling and SPARC (secreted protein acid rich in cysteine) expression in invasive ductal carcinomas of the breast. Virchows Arch 2005, 446:532-536.

10. Toccanier-Pelte MF, Skalli O, Kapanci Y, Gabbiani G: Characterization of stromal cells with myoid features in lymph nodes and spleen in normal and pathologic conditions. Am J Pathol 1987, 129:109-118.

11. Folse DS, Beathard GA, Granholm NA: Smooth muscle in lymph node capsule and trabeculae. Anat Rec 1975, 183:517-521.

12. Kohler CN: The actin-binding protein caldesmon is in spleen and lymph nodes predominately expressed by smooth-muscle cells, reticular cells, and follicular dendritic cells. J Histochem Cytochem 2010, 58:183-193.

13. Yamaoka K, Nouchi T, Marumo F, Sato C: Alpha-smooth-muscle actin expression in normal and fibrotic human livers. Dig Dis Sci 1993, 38:1473-1479.

14. Desmouliere A: Hepatic stellate cells: the only cells involved in liver fibrogenesis? A dogma challenged. Gastroenterology 2007, 132:2059-2062.

15. Dranoff JA, Wells RG: Portal fibroblasts: Underappreciated mediators of biliary fibrosis. Hepatology 2010, 51:1438-1444.

16. Barth PJ, Ebrahimsade S, Ramaswamy A, Moll R: CD34+ fibrocytes in invasive ductal carcinoma, ductal carcinoma in situ, and benign breast lesions. Virchows Arch 2002, 440:298-303.

17. Quaggin SE, Kapus A: Scar wars: mapping the fate of epithelialmesenchymal-myofibroblast transition. Kidney Int 2011, 80:41-50.

18. De Wever O, Demetter P, Mareel M, Bracke M: Stromal myofibroblasts are drivers of invasive cancer growth. Int J Cancer 2008, 123:2229-2238.

\section{doi:10.1186/s13000-014-0196-6}

Cite this article as: Catteau et al:: Myofibroblastic reaction is a common event in metastatic disease of breast carcinoma: a descriptive study. Diagnostic Pathology 2014 19:196.

\section{Submit your next manuscript to BioMed Central and take full advantage of:}

- Convenient online submission

- Thorough peer review

- No space constraints or color figure charges

- Immediate publication on acceptance

- Inclusion in PubMed, CAS, Scopus and Google Scholar

- Research which is freely available for redistribution 